\title{
Should a More Personalized Approach be applied to Hematopoietic Stem- Cell Transplantation?
}

\section{Stefan O Ciurea ${ }^{1 *}$, Piyanuch Kongtim ${ }^{1 \#}$, Gabriela Rondon ${ }^{1}$, Julianne Chen ${ }^{1}$, Ciprian Tomuleasa ${ }^{2}$ and Richard E Champlin ${ }^{1}$}

${ }^{1}$ Department of Stem Cell Transplant and Cellular Therapy, The University of Texas MD Anderson Cancer Center, Houston, Texas, USA

2luliu Hatieganu University of Medicine and Pharmacy, Romania

"Equal contribution

\begin{abstract}
Background: Allogeneic stem cell transplantation for older patients with hematological malignancies has generally been performed with reduced-intensity conditioning, as regimen-related toxicity prohibits a fully myeloablative conditioning regimen. We hypothesized that differences in intensity of conditioning are needed for different disease status.

Patients and Methods: We analyzed 115 older patients with AML (55 years or older) who received conditioning with fludarabine and melphalan, with a melphalan dose of $140 \mathrm{mg} / \mathrm{m}^{2}$ (FM140) (N=73) or $100 \mathrm{mg} / \mathrm{m}^{2}$ (FM100) (N=42).

Results: Overall, FM100 was associated with less TRM (18.1\% versus $43.5 \%, p=0.007)$, and acute GVHD (aGVHD) $(28.2 \%$ versus $36.7 \%, p=0.021)$ while relapse was similar $(21.5 \%$ versus $25.5 \%, p=0.489)$. The lower TRM with comparable relapse rate resulted in higher survival for FM100 as compared with FM140 conditioning regimen, 3 -year PFS was $60.2 \%$ and $28.6 \%(p=0.014)$. Conversely, patients with high-risk SWOG cytogenetics and adverse ELN risk had better survival outcomes with FM140 regimen due to lower relapse, while TRM was not different. In multivariable analysis, high-risk SWOG cytogenetics, adverse ELN risk and the development of grade 2-4 aGVHD predicted for worse PFS whereas using FM140 conditioning and aGVHD were an independent factor for TRM.

Conclusion: These results suggest as a proof-of-principle that a differential approach should be applied for patients receiving an allogeneic hematopoietic stem cell transplant, not only based on age, but also on disease characteristics impacting the risk of relapse. Further studies are needed to develop a more personalized approach to hematopoietic stem cell transplant recipients.
\end{abstract}

Keywords: Allogeneic hematopoietic stem cell transplantation; Transplantation for elderly patients; Personalized transplantation; Melphalan conditioning; Acute myeloid leukemia; High-risk cytogenetics

\section{Introduction}

Allogeneic hematopoietic stem-cell transplantation (HSCT) is curative for patients with various hematologic malignancies [1]. It has been traditionally limited to younger individuals and those without significant comorbidities because of higher regimenrelated toxicity associated with myeloablative conditioning. In an attempt to extend this therapy to older and unfit patients, a major step forward was the introduction of reduced-intensity conditioning (RIC) regimens [2], which rely primarily on the graft-versus-tumor (GVT) effect [3,4]. The combination of melphalan (100-180 mg/ $\mathrm{m}^{2}$ ) with a purine nucleotide analog (fludarabine or cladribine) has been introduced by our group, as melphalan is active against many hematological malignancies [5-8]. Several studies have reported promising outcomes of fludarabine and melphalan (FM) $140 \mathrm{mg} / \mathrm{m}^{2}$ conditioning regimen $[6,7,9]$. It remains unclear if a lower melphalan dose in this regimen could result in effective disease control. In this study we compared the outcomes of AML patients older than 55 years who were transplanted with fludarabine and two different melphalan doses, $100 \mathrm{mg} / \mathrm{m}^{2}$ (FM100) or $140 \mathrm{mg} / \mathrm{m}^{2}$ (FM140) as we hypothesized that a different intensity conditioning is needed for patients with different disease risk.

\section{Materials and Methods}

\section{Patients and transplant procedure}

We retrospectively analyzed outcomes of all 115 patients, $\geq 55$ years old with a diagnosis of AML who received their first transplant using an HLA matched related (MRD; $\mathrm{N}=47$ ), matched unrelated (MUD; $\mathrm{N}=44$ ), mismatched related (haploidentical) or mismatched unrelated donor (MMUD; $\mathrm{N}=24$ ) at our institution between 01/2000-05/2014 (Table 1). All patients had complete morphologic remission (CR 1 or CR2) at the time of transplant. Cytogenetic and molecular genetic data were appreciated according to both the SWOG and ELN risk categories $[10,11]$. The conditioning regimen consisted of fludarabine $25-30 \mathrm{mg} /$ $\mathrm{m}^{2}$ for $4-5$ days (days 6 or 5 to 2) with either melphalan $100 \mathrm{mg} /$ $\mathrm{m}^{2}(\mathrm{~N}=42)$ or $140 \mathrm{mg} / \mathrm{m}^{2}(\mathrm{~N}=73)$ on day 2. Patients who received mismatched transplants received also thiotepa $5-10 \mathrm{mg} / \mathrm{kg}$ or $2 \mathrm{~Gy}$ total body irradiation (TBI) as previously described by us [12]. GVHD prophylaxis for matched transplants consisted of tacrolimus, minimethotrexate. Anti-thymocyte globulin (ATG) was added for MUD and MMUD transplants [13]. Post-transplant cyclophosphamide plus tacrolimus and mycophenolate mofetil was the GVHD prophylaxis used for haploidentical transplants [14].

*Corresponding author: Stefan O Ciurea, M.D., Associate Professor, The University of Texas MD Anderson Cancer Centre, 1515 Holcombe Blvd., Unit 423, Houston, Texas-77030, USA, Tel: 713-745-0146; Fax: 713-794-4902; E-mail: sciurea@mdanderson.org

Received January 30, 2015; Accepted March 18, 2015; Published March 20 2015

Citation: Ciurea SO, Kongtim P, Rondon G, Chen J, Tomuleasa C, et al. (2015) Should a More Personalized Approach be applied to Hematopoietic Stem-Cell Transplantation? J Stem Cell Res Ther 5: 272. doi:10.4172/2157-7633.1000272

Copyright: (c) 2015 Ciurea SO, et al. This is an open-access article distributed under the terms of the Creative Commons Attribution License, which permits unrestricted use, distribution, and reproduction in any medium, provided the original author and source are credited. 
Page 2 of 7

\begin{tabular}{|c|c|c|c|c|c|}
\hline & \multicolumn{2}{|c|}{ FM100 } & \multicolumn{2}{|c|}{ FM140 } & \multirow[t]{2}{*}{$P$ value } \\
\hline & $\mathrm{N}=42$ & $\%$, Range & $N=73$ & $\%$, Range & \\
\hline Median age (year) & 63 & $55-75$ & 62 & $55-76$ & 0.821 \\
\hline Age $>65$ years & 15 & 35.7 & 23 & 31.5 & 0.684 \\
\hline Gender; female & 21 & 50 & 39 & 53.4 & 0.847 \\
\hline T-AML & 7 & 16.7 & 8 & 11 & 0.401 \\
\hline $\begin{array}{l}\text { SWOG Cytogenetic risk [10] } \\
\text { Favorable } \\
\text { Intermediate } \\
\text { High }\end{array}$ & $\begin{array}{c}4 \\
25 \\
13\end{array}$ & $\begin{array}{c}9.5 \\
59.5 \\
31\end{array}$ & $\begin{array}{l}2 \\
47 \\
24\end{array}$ & $\begin{array}{l}2.7 \\
64.4 \\
32.9\end{array}$ & 0.306 \\
\hline $\begin{array}{l}\text { ELN risk group [11] } \\
\text { Favorable } \\
\text { Intermediate-I } \\
\text { Intermediate-II } \\
\text { Adverse }\end{array}$ & $\begin{array}{c}3 \\
10 \\
11 \\
11\end{array}$ & $\begin{array}{l}7.3 \\
24.4 \\
26.8 \\
26.8\end{array}$ & $\begin{array}{c}3 \\
18 \\
12 \\
28\end{array}$ & $\begin{array}{l}4.1 \\
24.7 \\
16.4 \\
38.4\end{array}$ & 0.557 \\
\hline Beyond CR1 & 10 & 23.8 & 25 & 34.2 & 0.174 \\
\hline $\begin{array}{l}\text { SC source } \\
\text { PB } \\
\text { BM }\end{array}$ & $\begin{array}{l}17 \\
25\end{array}$ & $\begin{array}{l}40.5 \\
59.5\end{array}$ & $\begin{array}{l}50 \\
23\end{array}$ & $\begin{array}{l}68.5 \\
31.5\end{array}$ & 0.006 \\
\hline $\begin{array}{l}\text { Donor } \\
\text { MRD } \\
\text { MUD } \\
\text { MMUD and haploidentical donors }\end{array}$ & $\begin{array}{l}15 \\
15 \\
12\end{array}$ & $\begin{array}{l}35.7 \\
35.7 \\
28.6\end{array}$ & $\begin{array}{l}32 \\
29 \\
12\end{array}$ & $\begin{array}{l}43.8 \\
39.7 \\
16.4\end{array}$ & 0.32 \\
\hline Median CD34+ cell dose (cells/kg) & $3.77 \times 10^{6}$ & & $4.00 \times 10^{6}$ & & 0.653 \\
\hline $\begin{array}{l}\text { GVHD prohpylaxis } \\
\text { Tacrolimus+mini-methotrexate } \\
\text { Post-transplant cyclophosphamide }\end{array}$ & $\begin{array}{l}22 \\
17\end{array}$ & $\begin{array}{l}52.4 \\
40.4\end{array}$ & $\begin{array}{c}65 \\
6\end{array}$ & $\begin{array}{l}89 \\
8.2\end{array}$ & 0.143 \\
\hline
\end{tabular}

T-AML/MDS: Therapy Related AML/MDS; CR: Completer; SC: Stem Cell; PB: Peripheral Blood; BM: Bone Marrow; MRD: Matched Related Donor; MUD: Matched Unrelated Donor; MMUD: Mismatched Unrelated Donor

Table 1: Patients' and transplant characteristics.

\section{Statistical analysis}

The primary endpoint was progression-free survival (PFS). Secondary endpoints were overall survival (OS), relapse, treatmentrelated mortality (TRM), and incidence of acute and chronic GVHD. OS and PFS were calculated using the Kaplan-Meier method. Cumulative incidence (CI) function with competing risks method was used to estimate the endpoints of relapse, TRM, acute and chronic GVHD. Univariate comparisons of all endpoints were completed by the log-rank test. Variables were included in the multivariate model if they were conceptually important or if they approached $(\mathrm{p}<0.1)$ or attained statistical significance in the univariate regression. Analyses were performed using STATA statistics program version 13.

The Institutional Review Board (IRB) of UTMDACC approved the treatment protocols and this retrospective study. All patients provided written informed consent for transplant according to the Declaration of Helsinki.

\section{Results}

Demographics are listed in Table 1. Characteristics were similar between the two groups except more patients in the FM100 group received marrow stem cells $(59.5 \%$ vs. $31.5 \%, \mathrm{p}=0.006)$. After a median follow-up duration of 36.5 months, 49 patients (42.6\%) were alive and in remission. One hundred and five patients (91.3\%) had full donor chimerism at day 30 post-transplant including 37 patients $(88.1 \%)$ in FM100 and 68 patients (93.2\%) in FM140 ( $\mathrm{p}=0.097)$.

\section{Outcomes for all patients}

Overall, FM100 was associated with less TRM (18.1\% versus $43.5 \%$, $\mathrm{p}=0.007$ ), and acute GVHD (aGVHD). The Day-100 CI of aGVHD all grades and grade 2-4 in FM100 and FM140 groups was $28.2 \%$ versus $36.7 \%(\mathrm{p}=0.021)$, and $13.2 \%$ versus $21.5 \%(\mathrm{p}=0.013)$, respectively.
Infectious death was also lower in FM100 group compared with FM140 ( $8 \%$ versus $19 \%, p=0.048$ ). However, there was no significant difference in chronic GVHD (cGVHD), the 3-year CI of cGVHD was $39.3 \%$ versus $42.4 \%(\mathrm{p}=0.613)$, whereas extensive $\mathrm{cGVHD}$ was $18.7 \%$ versus $22.2 \%$, in the FM100 and FM140 group, respectively $(\mathrm{p}=0.286)$.

Relapse was similar between FM100 and FM140, 21.5\% versus $25.5 \%$ at 3 years $(p=0.489)$. The lower TRM with comparable relapse rate resulted in higher OS and PFS for FM100 as compared with FM140 conditioning regimen, 3-year PFS was $60.2 \%$ and $28.6 \%(\mathrm{p}=0.014)$ (Figure 1A), and 3 -year OS was $64.1 \%$ versus $30.4 \%$, respectively $(\mathrm{p}=0.005)$.

\section{Outcomes for different risk categories}

We first categorized patients according to SWOG cytogenetic risk and found that patients with favorable/intermediate-risk cytogenetics $(\mathrm{N}=78)$ had better PFS with FM100 $(\mathrm{N}=29)$ compared with FM140 $(\mathrm{N}=49)$ regimen (3-year PFS $76.5 \%$ versus $48.7 \%, \mathrm{p}=0.05)$ (Figure $1 \mathrm{~B})$, due to lower TRM (1-year TRM 14\% in FM100 versus 27.8\% in FM140, $\mathrm{p}=0.03$ ), while relapse was not different (3-year CI or relapse $9.4 \%$ in FM100 versus $24.3 \%$ in FM140, p=0.06). AML patients with highrisk cytogenetics $(\mathrm{N}=37)$ had better outcomes with FM140 $(\mathrm{N}=24)$ compared with FM100 conditioning regimen $(\mathrm{N}=13)$ (3-year PFS was $39.9 \%$ versus $17.6 \%, \mathrm{p}=0.013$ ) (Figure $1 \mathrm{C}$ ) due to lower relapse with FM140 regimen (3-year CI of relapse $28.5 \%$ versus $49.6 \%, p=0.026$ ), and comparable TRM (1-year TRM was $28.6 \%$ versus $20.2 \%, \mathrm{p}=0.14$ ).

When patients were categorized according to ELN risk groups, we have found that patients with favorable, intermediate-I or intermediateII who received FM100 had a significantly better PFS when compared with FM140 (3-year PFS was 76.9\% versus $26.7 \%, p=0.019$ ) (Figure 1D). This better survival resulted from a lower TRM (1-year TRM was $11.5 \%$ in FM100 versus 53.9\% in FM140, p=0.006), and comparable relapse $(11.6 \%$ versus $17.3 \%$ at 3 -years, $\mathrm{p}=0.487)$. Conversely, patients 
Citation: Ciurea SO, Kongtim P, Rondon G, Chen J, Tomuleasa C, et al. (2015) Should a More Personalized Approach be applied to Hematopoietic Stem-Cell Transplantation? J Stem Cell Res Ther 5: 272. doi:10.4172/2157-7633.1000272
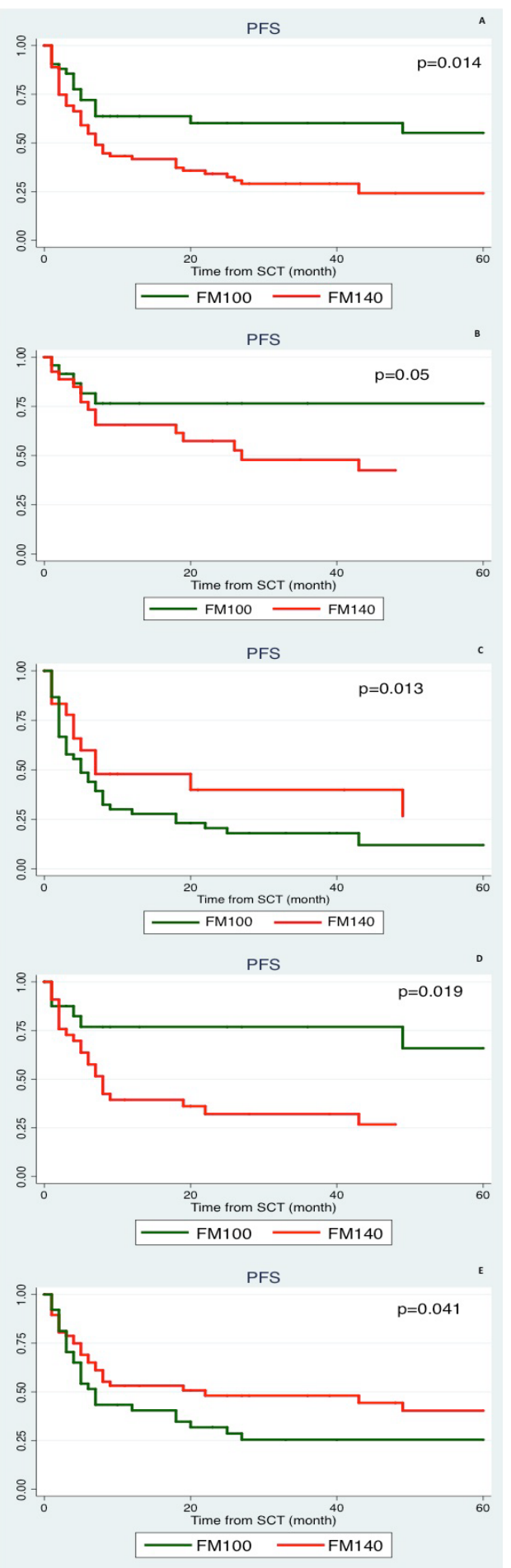

Figure 1: Kaplan-Meier estimates of progression-free survival according to the study group.

Panel A shows progression free survival of the entire cohort. Patients who received FM100 conditioning had significantly better progression-free survival compared with those who received FM140 conditioning $(p=0.014)$.

Panel B shows progression free survival of patients with favorable or intermediate SWOG cytogenetic risk. Patients received FM100 conditioning had significantly better progression-free survival compared with those who received FM140 conditioning $(p=0.05)$.

Panel C shows progression-free survival of patients with SWOG high-risk cytogenetics. A higher progression-free survival was seen in patients who received FM140 conditioning as compared to FM100 group $(p=0.013)$.

Panel D shows progression-free survival of patients with favorable or intermediate-I or intermediate-II risk group according to ELN classification. FM 100 was associated with a better progression-free survival as compared to FM140 conditioning $(p=0.019)$.

Panel E shows progression-free survival of patients with adverse risk according to ELN classification. Patients who received FM140 conditioning had a significantly better progression-free survival compared with FM140 conditioning $(p=0.041)$. 
Citation: Ciurea SO, Kongtim P, Rondon G, Chen J, Tomuleasa C, et al. (2015) Should a More Personalized Approach be applied to Hematopoietic Stem-Cell Transplantation? J Stem Cell Res Ther 5: 272. doi:10.4172/2157-7633.1000272

Page 4 of 7

with adverse ELN risk had better outcomes with FM140 regimen (3year PFS was 51.1\% in FM140 versus $25.3 \%$ in FM100 group, $\mathrm{p}=0.041$ ) (Figure $1 \mathrm{E}$ ) due to lower relapse ( $18.6 \%$ versus $47.8 \%, \mathrm{p}=0.031)$, while TRM was not different (29.9\% versus $25.2 \%, \mathrm{p}=0.345)$.

\section{Univariate and multivariate analysis}

Besides conditioning regimen intensity, other factors associated with poor PFS in univariate analysis were high-risk SWOG cytogenetics $(p=0.024)$, adverse ELN risk $(p=0.032)$, transplant beyond $2^{\text {nd }} C R$ $(\mathrm{p}=0.018)$, and grade $2-4$ aGVHD $(\mathrm{p}=0.023)$, while using MRD was associated with a better PFS $(\mathrm{p}=0.043)$. Allogeneic transplantation in patients older than 65 years was not associated with poor PFS when compared with patients younger than $65(\mathrm{p}=0.65)$.

In univariate analysis for TRM and relapse, aGVHD ( $p=0.021)$ was associated with higher TRM, while high risk SWOG $(\mathrm{p}=0.018)$ and adverse ELN risk $(\mathrm{p}=0.034)$ predicted higher relapse rate.

In multivariable analysis, only high-risk SWOG cytogenetics (HR 2.67, 95\% CI 2.06-3.24, $\mathrm{p}=0.017$ ), adverse ELN risk (HR 2.32, 95\%CI $1.87-2.64, \mathrm{p}=0.021$ ) and the development of grade 2-4 aGVHD (HR $1.79,95 \%$ CI 1.04-2.26, $\mathrm{p}=0.024)$ predicted for worse PFS. Using FM140 and aGVHD were an independent factor for TRM with HR of 1.79 (95\%CI 1.41-1.97, p=0.032) and 2.13 (95\%CI 1.84-2.53, p=0.003). For relapse, both high risk SWOG (HR 2.11, 95\%CI 1.86-2.44, $\mathrm{p}=0.003$ ) and adverse ELN risk (HR 1.94, 95\%CI 1.54-2.31, p=0.011) retained their significant in multivariate analysis for relapse.

\section{Discussion}

Allogeneic transplantation initially performed using myeloablative conditioning regimens showed feasibility of this procedure for older individuals (Ringden O JAMA 1993). However, most older or unfit patients would not be able to tolerate intense conditioning due to prohibitive TRM. While overall transplant outcomes for older individuals were found to be similar with a MAC compared with RIC, patients receiving RIC had lower incidence of aGVHD and TRM at the expense of a higher relapse rate (Aoudjhane Leukemia 2005). Consequently, RIC conditioning has become the new standard for transplantation of these patients [4,15-17].

Still, in hematopoietic stem-cell transplantation one-size-fitsall approach remains the norm, in part because of the relatively small number of patients treated. Here we demonstrate that a more customized approach is needed, and the intensity of conditioning should vary not only with age but also based on the disease treated. Some diseases, like AML with high-risk cytogenetics may not be so responsive to the GVT effects, might be more difficult to eliminate and consequently may require more intense conditioning. Low-risk patients may not need higher intensity conditioning usually associated with a higher TRM, and a lower intensity regimen, which generates reliably a full donor graft, may be the only conditioning needed in such patients. Other factors of importance for personalized treatment may be body mass index, co-morbidity index of the patient, risk of relapse and risk of graft-versus-host disease [18-20].

In conclusion, our results support the use of FM100 conditioning regimen for older individuals with hematological malignancies undergoing transplantation with matched or mismatched donors. We also suggest that a more individualized approach in needed in hematopoietic stem cell transplantation. Limitations in our study are mainly related to the retrospective nature of this study, and relatively small number of patients. These findings should be confirmed in a larger cohort of patients and, if confirmed, should be incorporated in prospective clinical trials of hematopoietic stem cell transplantation.

\section{Authorship Contribution}

SOC formulated the hypothesis, contributed to data collection and manuscript writing, PK collected and analyzed the data, and wrote the manuscript, GR $\mathrm{JC}$ contributed to data collection, reviewed and approved the manuscript, CT contributed with manuscript writing, REC contributed with data interpretation and manuscript writing.

\section{References}

1. Copelan EA (2006) Hematopoietic stem-cell transplantation. N Engl J Med 354 1813-1826. [PubMed]

2. Giralt S, Ballen K, Rizzo D, Bacigalupo A, Horowitz M, et al. (2009) Reducedintensity conditioning regimen workshop: defining the dose spectrum. Report of a workshop convened by the center for international blood and marrow transplant research. Biol Blood Marrow Transplant 15: 367-369. [PubMed]

3. Ciurea SO, Rodrigues M, Giralt S, de Lima M (2009) Aging, acute myelogenous leukemia, and allogeneic transplantation: do they belong in the same sentence? Clin Lymphoma Myeloma 9: 289-297. [PubMed]

4. McClune BL, Weisdorf DJ, Pedersen TL, Tunes da Silva G, Tallman MS, et al. (2010) Effect of age on outcome of reduced-intensity hematopoietic cell transplantation for older patients with acute myeloid leukemia in first complete remission or with myelodysplastic syndrome. J Clin Oncol 28: 1878-1887. [PubMed]

5. Giralt S, Thall PF, Khouri I, Wang X, Braunschweig I, et al. (2001) Melphalan and purine analog-containing preparative regimens: reduced-intensity conditioning for patients with hematologic malignancies undergoing allogeneic progenitor cell transplantation. Blood 97: 631-637. [PubMed]

6. Oran B, Giralt S, Saliba R, Hosing C, Popat U, et al. (2007) Allogeneic hematopoietic stem cell transplantation for the treatment of high-risk acute myelogenous leukemia and myelodysplastic syndrome using reduced-intensity conditioning with fludarabine and melphalan. Biol Blood Marrow Transplant 13 454-462. [PubMed]

7. Popat U, de Lima MJ, Saliba RM, Anderlini P, Andersson BS, et al. (2012) Longterm outcome of reduced-intensity allogeneic hematopoietic SCT in patients with AML in CR. Bone marrow transplant 47: 212-216. [PubMed]

8. Bayraktar UD, Bashir Q, Qazilbash M, Champlin RE, Ciurea SO (2013) Fifty years of melphalan use in hematopoietic stem cell transplantation. Biol Blood Marrow Transplant 19: 344-356. [PubMed]

9. De Lima M, Anagnostopoulos A, Munsell M, Shahjahan M, Ueno N, et al. (2004) Nonablative versus reduced-intensity conditioning regimens in the treatment of acute myeloid leukemia and high-risk myelodysplastic syndrome: dose is relevant for long-term disease control after allogeneic hematopoietic stem cell transplantation. Blood 104: 865-872. [PubMed]

10. Slovak ML, Kopecky KJ, Cassileth PA, Harrington DH, Theil KS, et al. (2000) Karyotypic analysis predicts outcome of preremission and postremission therapy in adult acute myeloid leukemia: a Southwest Oncology Group/Eastern Cooperative Oncology Group Study. Blood 96: 4075-4083. [PubMed]

11. Dohner H, Estey EH, Amadori S, Appelbaum FR, Buchner T, et al (2010) Diagnosis and management of acute myeloid leukemia in adults: recommendations from an international expert panel, on behalf of the European LeukemiaNet. Blood 115: 453-474. [PubMed]

12. Ciurea SO, Mulanovich V, Saliba RM, Bayraktar UD, Jiang Y, et al. (2012) Improved early outcomes using a $\mathrm{T}$ cell replete graft compared with $\mathrm{T}$ cell depleted haploidentical hematopoietic stem cell transplantation. Biol Blood Marrow Transplant 18: 1835-1844. [PubMed]

13. Bashir Q, Andersson BS, Fernandez-Vina M, de Padua Silva L, Giralt S, et al (2011) Unrelated donor transplantation for acute myelogenous leukemia in first remission. Biol Blood Marrow Transplant 17: 1067-1071. [PubMed]

14. Luznik L, O'Donnell PV, Symons HJ, Chen AR, Leffell MS, et al. (2008) HLAhaploidentical bone marrow transplantation for hematologic malignancies using nonmyeloablative conditioning and high-dose, posttransplantation cyclophosphamide. Biol Blood Marrow Transplant 14: 641-650. [PubMed]

15. Thomas ED (1983) Karnofsky Memorial Lecture. Marrow transplantation for malignant diseases. J Clin Oncol 1: 517-531. [PubMed] 
Citation: Ciurea SO, Kongtim P, Rondon G, Chen J, Tomuleasa C, et al. (2015) Should a More Personalized Approach be applied to Hematopoietic Stem-Cell Transplantation? J Stem Cell Res Ther 5: 272. doi:10.4172/2157-7633.1000272

Page 5 of 7

16. Champlin R (2013) Reduced intensity allogeneic hematopoietic transplantation is an established standard of care for treatment of older patients with acute myeloid leukemia. Best Pract Res Clin Haematol 26: 297-300. [PubMed]

17. Champlin $\mathrm{R}$ (2011) Reduced-intensity allogeneic hematopoietic transplantation should be considered a standard of care for older patients with acute myeloid leukemia. Biol Blood Marrow Transplant 17: 1723-1724. [PubMed]
18. Fuji S, Takano K, Mori T, Eto T, Taniguchi S, et al. (2014) Impact of pretransplant body mass index on the clinical outcome after allogeneic hematopoietic SCT. Bone marrow transplant 49: 1505-1512. [PubMed]

19. Sorror ML, Storb RF, Sandmaier BM, Maziarz RT, Pulsipher MA, et al. (2014) Comorbidity-age index: a clinical measure of biologic age before allogeneic hematopoietic cell transplantation. J Clin Oncol 32: 3249-3256. [PubMed] 
Citation: Ciurea SO, Kongtim P, Rondon G, Chen J, Tomuleasa C, et al. (2015) Should a More Personalized Approach be applied to Hematopoietic Stem-Cell Transplantation? J Stem Cell Res Ther 5: 272. doi:10.4172/2157-7633.1000272

Page 6 of 7

20. Kongtim P, Di Stasi A, Rondon G, Chen J, Adekola K, et al. (2015) Can a Female Donor for a Male Recipient Decrease the Relapse Rate for Patients With Acute Myeloid Leukemia Treated With Allogeneic Hematopoietic Stem Cell Transplantation? Biol Blood Marrow Transplant 21: 713-719. [PubMed] 
Citation: Ciurea SO, Kongtim P, Rondon G, Chen J, Tomuleasa C, et al. (2015) Should a More Personalized Approach be applied to Hematopoietic Stem-Cell Transplantation? J Stem Cell Res Ther 5: 272. doi:10.4172/2157-7633.1000272 